\title{
Effective Tension in Robbins's Economic Methodology
}

\author{
Lionel Robbins's Essay on the Nature \\ and Significance of Economic Science - $75^{\text {th }}$ Anniversary \\ London School of Economics - London, England \\ December 10-11, 2007
}

\author{
D. Wade Hands \\ Department of Economics \\ University of Puget Sound \\ Tacoma, WA 98416 USA \\ hands@ups.edu \\ 7,191 Words \\ Version 1.1
}

\begin{abstract}
Lionel Robbins 1932 Essay is one of the most influential methodological works in $20^{\text {th }}$ century economics. This said, the Essay is not philosophically seamless; it exhibits certain tensions that are not easily reconciled within any specific philosophical characterization of scientific knowledge. The paper discusses these issues, but also emphasizes that these tensions did not inhibit the influence of the Essay within economics. In fact, it is argued that these philosophical tensions actually contributed to its influence. Marginalist economics was under attack from a number of different directions and Robbins's Essay provided an effective response these critics - a response that would have been much less effective if Robbins had consistently adopted (only) one of the prevailing philosophical conceptions of scientific knowledge. It was a methodology for economics, not for philosophers, and its influence needs to be understood within the historical context of marginalist economics in the 1930s.
\end{abstract}


An eminent industrial psychologist once genially assured me that "if people only understood industrial psychology there would be no need for Economics". With considerable interest, I at once enquired his solution of a problem of foreign exchange which had been perplexing me, but to my great mortification no answer was forthcoming. [Robbins, 1932, p. 32, cut from the second edition]

\section{Introduction}

Lionel Robbins's 1932 Essay $^{1}$ is one of the most important methodological works in twentieth century economics. In fact it is one of a small handful of the most influential methodologically-oriented publications - article or book - in the entire history of economics. Robbins defended a number of claims about the nature, significance, and policy relevance of economic science in the Essay, but the most enduring were his basic definition of economics and his argument against the possibility of interpersonal utility comparisons.

Robbins's Essay has been the subject of extensive methodological commentary - with Terence Hutchison (1938) delivering one of the earliest and most influential - although less, perhaps, than some other major methodological works, particularly John Stuart Mill (1874) and Milton Friedman (1953). The majority of the critical commentary has focused on the degree of a priorism of Robbins position and his arguments against interpersonal utility comparisons (see the discussion in surveys of methodology such as Blaug 1992, Caldwell 1994, and Hands 2001).

This paper also offers methodological commentary on Robbins's Essay, but with an new twist. First, I will argue there are certain philosophical tensions in Robbins's essay. By this, I mean it contains arguments and/or positions that are difficult to reconcile with other positions within

1 The first edition of An Essay on the Nature \& Significance of Economic Science was published in 1932, followed by a second edition in 1935 (Robbins 1952). The central thesis and most aspects of the argument were the same for both editions, although there were also some significant changes. Some these changes will be discussed below. Essay will be used throughout to refer to the book in general (that is, to refer to arguments common to both editions). 
the text, and/or with any particular well-established philosophical positions (either from Robbins's day or ours). Of course these philosophical tensions - recognized or not - did not adversely affect the reception of Robbins's methodological ideas within the economics profession. Second - and here is the twist - I will argue that not only did these tensions not prevent Robbins's position from becoming influential, if these tensions had not existed within the text it would not have been as influential as it was; the tensions are precisely what allowed Robbins's approach to accommodate, and steer a path through, the complex problem-situation that confronted marginalist economics during the 1930s.

\section{Robbins's Methodology}

This section will review three important aspects of Robbins's characterization of economics in the Essay: his definition of economics, his critique of interpersonal utility comparisons, and his introspective approach to knowledge about individual economic agents. The first two of these are well-known and thus require little elaboration. The third has received less attention and requires more discussion.

Robbins definition of economics from chapter one of the Essay still graces the first chapter of almost every introductory economics textbook.

Economics is the science which studies human behavior as a relationship between ends and scarce means which have alternative uses. (Robbins, 1932, p. 15)

On this definition economics does not study a "kind" of behavior - such as behavior involving money or wealth - but rather an "aspect" of almost all human behavior. The ends are taken as given ("as economists we cannot go behind changes in individual valuations" ibid., 115) and they need not be self-interested (they "may be noble or they may be base" ibid., p. 24). What matters is that the means for achieving the end are scarce and thus a choice must be made.

Economics is not concerned at all with any ends as such. It is concerned with ends in so far as they affect the disposition of means. It takes the ends as given scales of relative valuation, and enquires what consequences follow in regard to certain aspects of behavior. (ibid., p. 29)

The Robbins's definition basically equates economics with rational choice, and that has been the main point of contention about the definition over the years (i.e. should economics be defined more broadly). 
Robbins argued that his definition was not meant to change professional practice, but rather to simply capture what most economists had long been doing (Backhouse and Medema 2007).

Equally well-established - although certainly more controversial and receiving a lot more attention over the years (in both opposition and support) - is Robbins's argument against interpersonal utility comparisons in chapter six of the Essay. As he explains:

It is a comparison which necessarily falls outside the scope of any positive science. To state that A's preference stands above B's in order of importance is entirely different from stating that A prefers $\mathrm{n}$ to $\mathrm{m}$ and $\mathrm{B}$ prefers $\mathrm{n}$ and $\mathrm{m}$ in $\mathrm{a}$ different order. It involves an element of conventional valuation. Hence it is essentially normative. It has no place in pure science. (ibid., p. 123)

Economics is a positive science while interpersonal utility comparisons are normative judgments of value, and between "the generalizations of positive and normative studies there is a logical gulf fixed which no ingenuity can disguise and no juxtaposition in space or time bridge over (ibid., p. 132). This means, in particular, that the well-known utilitarian argument for increased income equality based on the diminishing marginal utility of money is "in fact entirely unwarranted by any doctrine of scientific economics" (ibid., p. 121) and is thus "entirely illegitimate" (ibid., p. 125).

The third aspect of Robbins's argument to consider here has attracted less interest than either his definition or his arguments against interpersonal utility comparisons; it is the introspective character of the knowledge about individual agents that Robbins ascribes to the economic scientist. There was some discussion of this issue in the first edition particularly in chapter four - but it received significantly more attention in the second edition. It is not clear whether Robbins changed his mind on this issue, or whether it was simply a matter of using the second edition to improve what he had said, or tried to say, in the earlier text. In both editions Robbins explains that the knowledge we have about the preferences of individual agents does not come from objective scientific observation based on the type of controlled experiments available in the natural sciences (ibid., p. 74). But if not on experimental evidence, then what is such knowledge based on?

In the first edition - here sounding more Misean than in the second edition - Robbins makes the case that preference orders (scales of relative valuations) are simply a necessary consequent of scarcity- 
constrained economic choice: "the elucidation of the implications of the necessity of choice in various assumed circumstances" (ibid., p. 83).

[A]11 that is assumed in the idea of scales of valuation is that different goods have different uses and that these different uses have different significances for action, such that in a given situation one use will be preferred before another (ibid., p. 86)

Although this argument was retained in the second edition, Robbins added a number of additional pages in chapter four that put more emphasis on the fact that agents have preferences that consistently order various outcomes and also stressed the introspective nature of our knowledge of these preferences.

The ability to order various possible choices is presented as fundamental to economic choice in the second edition: the "foundation of the theory of value is the assumption that the different things that the individual want to do have a definite importance to him, and can be arranged therefore in a certain order" (Robbins, 1952, p. 75). ${ }^{2}$

The propositions of economic theory, like all scientific theory, are obviously deductions from a series of postulates ... The main postulate of the theory of value is the fact that individuals can arrange their preferences in an order, and in fact do so. (ibid., pp. 78-79)

Not only do individuals arrange their preferences in an order, it is a consistent (what we would now call transitive) order.

The celebrated generalization that in a state of equilibrium the relative significance of divisible commodities is equal to their price, does involve the assumption that each final choice is consistent with every other, in the sense that if I prefer A to B and B to C, I also prefer A to C ... (ibid., pp. 91-92, emphasis added)

Robbins is also more clear in the second edition about both where this knowledge does not come from - "We do not need controlled experiments to establish their validity" (ibid., p. 79) - and where is does come from; it comes from introspective "inner experience" (ibid., p. 88). Even though the key postulates of economics do not rest on any particular psychological theory, it is clear that

2 This, and the next nine quotes are from the material added to the second edition and are not contained in the first edition. 
... they do most unquestionably involve elements which are of a psychological - or perhaps better said a psychical nature ... the subjective or psychological theory of value; and, as we have seen, it is clear that the foundation of this theory is a psychical fact, the valuations of the individual. (ibid., pp. 86-87)

The psychological fact is that individuals have ordered and consistent (transitive) preferences and make valuations on the basis of those preferences.

Of course Robbins is not suggesting that all knowledge relevant to economics comes from introspection. There are also many things that we know based on empirical observations of the standard "objective" or "interpersonal" sort - what today we would simply call "observations" including the fact of scarcity, trade, competition, monopoly, and such (in addition to the obvious rocks and trees). Introspection was certainly not the source of all knowledge for Robbins, but it was the source of our knowledge that individuals have preferences and can arrange the desirability of various outcomes in a consistent order.

Robbins makes it entirely clear in the pages added to the second edition that this is not - and in fact is completely at odds with - the kind of human science a behaviorist would authorize. ${ }^{3}$ Behaviorism restricts human science to only that which is objective and interpersonally observable, and the valuations that undergird the postulates of economics are subjective an non-observable. For the behaviorist:

Valuation is a subjective process. We cannot observe valuation. It is therefore out of place in a scientific explanation. (ibid., p. 87)

Those who would exclude such subjective valuations reflect "an attitude which is very frequent among those economists who have come under the influence of Behaviourist psychology or who are terrified of attack from exponents of this queer cult" (ibid., p. 87). Economic actions are forward-looking and based on expectations of future events, and "It is

3 Behaviorism is mentioned in passing in the first edition but is given much more attention in the second edition, particularly in the material added in chapter four (much of what was added originally appeared in Robbins 1934). In the preface to the second edition Robbins explains that certain readers of the first edition "have accused me of "behaviourism"' (p. x) and his desire to set the record straight is undoubtedly one of the reasons for his explicit critical discussion of behaviorism in the second edition. But, as I will argue below, there is also a connection with his views on the definition of economics and interpersonal utility comparisons. 
obvious that what people expect to happen in the future is not susceptible of observation by purely behaviourist methods" (ibid., p. 88). Behaviorists would reconstruct social science entirely in the image of natural science and such a social science is unable to capture the purposefulness, the valuations, or the choice that is essential to understanding economic behavior. Economics is a science for Robbins, but it is not a science exactly like, or strictly following the method of, the natural sciences.

... the procedure of the social sciences which deal with conduct, which is in some sense purposive, can never be completely assimilated to the procedures of the physical sciences. It is really not possible to understand the concepts of choice, of the relationship of means and ends, the central concepts of our science, in terms of observation of external data. The conception of purposive conduct in this sense does not necessarily involve any ultimate indeterminism. But it does involve links in the chain of causal explanation which are psychical, not physical, and which are, for that reason, not necessarily susceptible of observation by behaviourist methods. (ibid., pp. 89-90)

Although Robbins's explicit anti-behaviorism comes out more clearly in the second than the first edition of the Essay, it is a position that he consistently endorsed in later work. As Robbins explains in 1953:

Pure behaviourism has not proved a particularly helpful method in psychology proper. Why, at this time of day, we should go out of our way to shackle ourselves with its selffrustrating inhibitions is not at all relevant ... I do not think that it is sensible to restrict our generalizations to observables and I see no objection to explanation in terms of assumed calculations and estimates. (Robbins, 1953, p. 102)

And again a few years before his death in 1984:

Influenced presumably by behaviourism in psychology, there are those who urge that in economics we must exclude any hypothesis which relies on conceptions which are not directly observable ... I confess that I fail to see the necessity, or indeed the desirability of the self-denying ordinance. (Robbins, 1981, p. 2) 
It is important to note that even though Robbins considered it necessary to "invoke elements of a subjective or psychological nature" (1952, p. 88), this in no way commits economic theory to the doctrine of "psychological hedonism" (1932, pp. 83-86). In both editions - and in essentially identical language ${ }^{4}$ - Robbins argues that economics does not in any way depend on the calculus of pleasure and pain of psychological hedonism. It is true that certain early marginalists were sympathetic to hedonism and it figured prominently in their economic theories, but these "hedonistic trimmings" were "incidental to the main structure" of the theory which "is capable of being set out and defended in absolutely nonhedonistic terms (ibid., p. 86). For Robbins, economic agents have consistent preferences, but these preferences are not related in any direct way to any subjective feelings of pleasure or pain the agent might experience from the possession or consumption of the relevant goods.

Robbins vision of economic theory clearly excludes both psychological hedonism and behaviorism. The first is a discredited mental state-based theory of human valuation liked to utilitarian ethics, while the second is an overly scientistic attempt to force economics into the purely observational straightjacket of the natural sciences. Both are inappropriate for an economic science concerned exclusively with "securing of given ends with least means" (1932, p. 129 and 1952, p. 145). As I will argue in more detail in the next section, these twin exclusions put Robbins on a bit of a tightrope in the Essay. On one side is psychological hedonism which was not only the psychological foundation of early (at least British) marginalism, it was also linked to classical economics through Mill and others as well as to introspection (which Robbins supported). On the other side, behaviorism was in vogue in psychological circles when Robbins was writing and was increasingly promoted as the only truly scientific approach to human behavior. Robbins wanted to improve the scientific credibility of the discipline during the heyday of behaviorism, but to do so without out sacrificing the core tenets of marginalism and while endorsing introspectionism. A tightrope indeed.

\footnotetext{
4 It is not relevant to the argument in this paper, but interesting nonetheless, that many of the changes that Robbins made to the second edition seemed to have nothing to do with either modifying his position or making it more clear, but were simply a matter of toning down the rhetoric from the first edition. One nice example of this occurs in this section of chapter four where he is criticizing those who attack economics because it rests on out-of-date psychological (i.e. hedonistic) foundations. In the first edition they "are the happy hunting ground of the charlatan and quack" (1932, p. 83) while in the second edition they have "minds averse to the effect of exact thought" (1952, p. 83). Earlier a sentence referring to Marshall's "spineless platitudes" (1932, p. 65) was dropped entirely from the second edition, and later something that filled him with "unutterable fury" (1932, p. 126) in the first edition, only left him with "indignation" (1952, p. 142) in the second edition. There are many other such examples.
} 
I will close this section with a nice example of this delicate balance Robbins maintains between hedonism and behaviorism from chapter four of the Essay where he is criticizing psychological hedonism and separating it from marginalist economics. In the first edition he says:

All that we need to assume is the obvious fact that different possibilities offer different stimuli to behaviour, and that these stimuli can be arranged in order of their intensity. (1932, p. 86).

Although this sentence does make the point against hedonism, the use of the term "stimuli," and particularly "stimuli to behaviour," could easily be given a behaviorist interpretation. In the second edition this sentence becomes:

All that we need to assume as economists is the obvious fact that different possibilities offer different incentives, and that these incentives can be arranged in order of their intensity. (1952, p. 86)

This is a statement less likely to bring comfort to either a hedonist or a behaviorist.

\section{Tensions in Robbins's Essay}

In this section I would like to discuss two of the tensions - broadly philosophical tensions - in the Essay. The theme of both of these tensions was suggested by the last few paragraphs of the previous section. The first concerns introspection and the second concerns interpersonal utility comparisons. It is perhaps useful to talk as if they were two separate issues, but in fact they are simply two facets of the balancing act discussed in the previous section.

Whether Robbins was merely reporting what most economists already believed, or trying to change the character of the discipline, is really irrelevant to the tensions discussed in this section. The fact is, whether he was reporting or redefining, Robbins's Essay had three goals - to define economic science as the study of scarcity-constrained rational choice, to put economics on what was perceived to be a firmer epistemological foundation (which entailed moving away from psychological hedonism), and to persuasively make the argument against interpersonal utility comparisons - and he delivered effectively on all three: the first and third almost single-handedly, and the second with the help of his LSE colleagues Hicks and Allen (1934) and the various other key figures in the ordinalist revolution (Hicks 1982). Achieving these 
three goals would provide marginalist economics with exclusive rights to the title of scientific economics; the profession would still need historical data and other empirical evidence provided by the institutionalist or historical schools (Robbins mentions "a Schmoller, a Veblen, or a Hamilton," 1932, p. 105), but it leaves the pure science of economics to marginalism alone. It would also provide a response to the vast array of critics who based their criticism of marginalism on its hedonistic foundations: some advocating a more up-to-date psychological theory (Robbins mentions Cassel and Pareto, pp. 87-88, 1952) and some advocating direct statistical-empirical estimation of market demand functions thus skipping individual choice and/or psychology altogether (Robbins discusses Mitchell in this regard, 112-114, 1952). And finally of course, the argument against interpersonal utility comparisons would undercut the scientific justification of a wide range of utilitarian-inspired income redistributions schemes (from moderate Marshallian to Fabian socialist). Clear goals that were effectively accomplished, so where is the tension?

Robbins introspectionism appears to be decidedly at odds with the goal of putting economic theory on a more solid scientific foundation. In Mill's day, empiricists generally accepted introspection - inner observation - as a legitimate form of observational experience, but by the 1930s this had changed. By the first quarter of the twentieth century most philosophers and scientists restricted the experiential basis of empirical science exclusively to "objective" - that is, interpersonally observable - evidence. There were many forces contributing to this change but the decline of strict Descartian dualism, the rise of experimental psychology, the ascension of positivist ideas in the philosophy of science, and the rise of behaviorism in psychology, were all clearly important (and interrelated) factors. By the time Robbins was writing the Essay the intellectual tide in both psychology and epistemology had clearly turned in favor of intersubjective observability and behaviorism, and away from introspection. As B. F. Skinner summed up the attitude many years later: "A completely independent science of subjective experience would have no more bearing on a science of behavior than a science of what people feel about fire would have on the science of combustion" (Skinner, 1974, p. 243).

Given that Robbins was concerned about the epistemic status of marginalist economics - particularly the criticisms by institutionalists and others that economics had not kept up with the times in psychology and empiricist epistemology - and wanted to ground it on more acceptable foundations, it seems rather strange that Robbins would retain introspection as the basis for his core presuppositions about consumer preference and choice. In the 1930s, the heady days of 
positivism and behaviorism, why not turn to behaviorism for the philosophical support of marginalism (as the young Paul Samuelson attempted to do a few years later in 1938)? It was clear that psychological hedonism had to go, but why not go all the way and also reject the introspectionism of Mill and the early marginalists?

One way to try to answer this question would be to examine the various intellectual influences and personal contacts during Robbins's education and in the years leading immediately preceding publication of the Essay. Some excellent research already exists in this regard (Howson 2004, O'Brien 1990 and others) and more archival-based studies are currently underway, but my approach is more exegetical and contextual than archival. In this section I will argue that while resisting positivist behaviorism may have been at odds with one of Robbins's three goals making the case for more epistemically acceptable foundations for marginalism - it was in fact quite consistent with the other two: the scarcity constrained choice definition of economics and the argument against interpersonal utility comparisons. Introspection served these two purposes, but behaviorism would have been a serious handicap. As the good marginalist he was, Robbins was willing to make tradeoffs among the Essay's three goals on the basis of the various constraints he faced. In the next section I will examine how Robbins's choices were effective solutions to the problem situation facing marginalist economics more generally during the 1930s (and not that of psychology or positivist philosophy). The bottom line will be that Robbins needed introspection and the profession needed Robbins's solution.

First consider Robbins's definition of economics as scarcity constrained choice. Notice it is choice not conditioned response or mechanically determined action. As the various Robbins quotes in the previous section make clear, economics was exclusively about choice and such volitional action is precisely what behaviorism rules out. Behaviorism not only black-boxed what went on inside the mind at the moment an action was untaken, it established law-like empirical regularities connecting the antecedent to behavior (stimulus) and the behavioral consequent (response). The entire epistemic foundation of behaviorism is based on finding such constant conjunctions of interpersonally observable facts: stimulus $(\mathrm{x})$ precedes, and has a law-like connection to, behavior $(\mathrm{y})$, making $y=f(x)$ the only form of scientifically legitimate behavioral law. As John Watson explains in his classic statement of behaviorism:

The behaviorist asks: Why don't we make what we can observe the real field of psychology? Let us limit ourselves to things that can be observed, and formulate laws concerning only those things. Now what can we observe? Well, we can 
observe behavior - what the organism does or says ... The rule, or measuring rod, which the behaviorist puts in front of him always is: Can I describe this bit of behavior I see in terms of "stimulus and response"? (Watson, 1924, p. 6)

Now of course the contemporary psychologist or philosopher of mind may protest and say that this is a very early, strict, and simplistic characterization of behaviorism and that over time the program became much more sophisticated and encompassed a much wider methodological stance. True enough, but the point is irrelevant here. The behaviorism that Robbins faced in the 1930s - and the behaviorism that was continually being thrown up to marginalist economists as the cutting edge of scientific psychology by institutionalists and others - was precisely this strict early behaviorism, and that version of behaviorism was not a methodological position that could underwrite economics as the science of rational choice. Remember for Robbins "no purposive action" meant "no economic phenomena" (Robbins, 1952, p. 93) and driving occult concepts such purpose and teleology out of psychology was precisely what behaviorism was all about. Moving sharply in the behaviorist direction during the 1930s would have facilitated the effort to demonstrate that marginalism had effectively shaken off its nineteenth century hedonistic past and was now truly scientific, but it would also have meant that economics could not be defined as the science of scarcity-constrained rational choice.

Notice also that retaining a certain element of introspective knowledge and resisting the behaviorist-positivist strictures of natural science, Robbins could not only underwrite his scarcity-constrained choice-based definition of economics, it even allowed him to make the case that economics was on more solid foundations than natural science. Natural science had only "objective" observation; economics had both observation and introspection.

In Economics, as we have seen, the ultimate constituents of our fundamental generalisations are know to us by immediate acquaintance. In the natural sciences they are known only inferentially. There is much less reason to doubt the counterpart in reality of the assumption of individual preferences than that of the assumption of the electron. (ibid., p. 105)

Although from the perspective of philosophy of science (then or now) Robbins use of introspection leaves his characterization of scientific economics vulnerable to attack, from Robbins's perspective it provided an appropriate foundation for his choice-based conception of economics 
and gave the discipline a potentially more solid foundation than mere observation-bound natural science.

Similar remarks can be made about Robbins's argument against interpersonal utility comparisons. The first thing to note is that Robbins used introspection to establish the argument against interpersonal utility comparisons. As argued above, Robbins recognized two sources of knowledge: knowledge based on empirical observation (of the now standard "objective" sort) and the introspective knowledge that we have subjective preferences that can arrange goods in a consistent order. Since we cannot see inside the minds of others, we do not have objective knowledge of their individual subjective preferences (and of course behaviorism doesn't help since it "explains" behavior without knowledge of, or even reference to, such preferences/goals/desires). But one also does not have introspective knowledge of the minds of others; inner observation will tell us that we order goods but not that others do so. Since interpersonal utility comparisons are neither empirically or introspectively observable, they are not scientifically legitimate. Of course we continually make such interpersonal comparisons in everyday life which Robbins fully admits - but like so many of our folk practices such inferences have no scientific standing.

Introspection does not enable $\mathrm{A}$ to discover what is going on in B's mind, nor B to discover what is going on in A's. There is no way of comparing the satisfactions of different people. (Robbins, 1932, p. 124 and 1952, p. 140, emphasis added)

And as he explains in later work, the problem is that interpersonal comparisons involve neither (objective) observation nor introspection.

The assumptions of the propositions which did not involve interpersonal comparisons of utility were assumptions which had been verified by observation or introspection, or, at least, were capable of such verification. The assumptions involving interpersonal comparison were certainly not of this order. (Robbins, 1938, p. 637, emphasis added)

I still cannot believe that it is helpful to speak as if interpersonal comparisons of utility rest upon scientific foundations - that is, upon observation or introspection. (ibid., p. 640, emphasis added)

To see how important introspection is to this position, suppose for the sake of argument that one takes the position that the only knowledge we have of human action/behavior is that which is based on (non- 
introspective) empirical observation. In this case what we would know about any human behavior would have the same source, objective observation, whether it was the behavior of ourselves or others. Thus if our objective observations could somehow tell us about the preferences of others (the promise some neuroeconomists see for MRI and other neural imaging) then we could learn about our own preferences in the same way, and vice versa; if we could infer our own preferences from various empirical observations of our behavior then we could apply the same technique to others. In any case, the knowledge we have of others would be the same as our self-knowledge. Thus we would have either: 1) no knowledge of our own preferences or, 2) we would have the ability to make interpersonal utility comparisons. Introspection as the source of self-knowledge provides Robbins a way around this problem. Since introspection is the source of our self-knowledge it is qualitatively different than the objective knowledge we have of others. ${ }^{5}$

Thus we find there are certain tensions in Robbins's tripartite project of defining economics as choice under scarcity, improving the scientific foundations of choice theory, and banning interpersonal utility comparisons from scientific economics. The introspectionism that works so effectively in preserving volitional choice and against interpersonal utility comparisons, seems, in the context of the 1930s, to undermine his effort to provide economics with more philosophically and psychologically acceptable foundations. A "purer" position, philosophically and psychologically, such as behaviorism, would facilitate one aspect of Robbins's project while undermining others. Robbins's project enjoyed a substantial measure of success, but it did so without the relative seamlessness associated with certain earlier approaches such as Mill's.

\section{The Methodological Problem-Situation of Marginalism in the 1930s}

The previous section focused on Lionel Robbins the individual: what he was trying to accomplish in the Essay and some of the tensions that developed among the various parts of his project. This section will focus on the economics profession. Tensions or not, Robbins three core arguments in the Essay came to be generally accepted within the economics profession during the decades following its publication. There were criticisms of course - as mentioned above, most centering around his criticism of interpersonal utility comparisons and the question of the a priorism of his position - but his definition certainly became standard and there was general acceptance that the ordinal revolution (with contributions from many others) had helped solve the foundational and

5 As some have pointed out over the years (Little 1949, Walsh 1996) this still leaves Robbins with the question of how we know other minds exist at all, but that issue is beyond the scope of the current discussion. 
epistemological problems associated with the earlier psychological hedonism. ${ }^{6}$ This section will argue that if one understands the problem situation facing marginalism during the 1930s - the goals and constraints the profession faced - the broad-based endorsement of Robbins position becomes quite understandable. Although tensions existed that might have concerned members of other scholarly communities (e.g. philosophy or psychology), the constellation of arguments that Robbins provided appeared to offer a reasonable solution to the various problems facing marginalism at the time. Since Robbins's stance on interpersonal utility comparisons was contested at least until the second half of the twentieth century - and again recently (e.g. Kahneman and Krueger 2006) - this section will focus on the other two main aspects of Robbins's position: the definition of economics and the effort to find more adequate scientific foundations for rational choice theory.

As discussed above, marginalism was under attack from a variety of different directions in the early 1930s: from Marxists and historicists of various stripes in Europe and from institutionalists in North America. And one of the consistent critical claims was that marginalist economics was based on psychological hedonism, and that such hedonism was an outmoded psychological theory that was either empirically inadequate (false), or simply untestable, but in either case, certainly not the kind of foundation that would should use to build the house of scientific economics. Of course critics offered a wide range of alternative approaches to economic phenomena-Marxism, various institutionalisms, purely empirical/statistical approaches, and a host of others - but none of these were consistent with the core impulses of marginalism. Marginalism in the 1930s thus faced a scientific credibility problem. The problem was to develop an economic theory that was consistent with the core marginalist commitments, but to do so without

6 One of course needs to be careful talking about the "economics profession" as if "the profession" were homogeneous. There were certainly Marxists, institutionalists, and heterodox economists of a variety of other stripes that never accepted any of Robbins's three main propositions. One is tempted to use the term "mainstream economics" in this context, but in the 1930s and 1940s many of those supporting Robbins position were opposed to Keynesian macroeconomics (a version of which did eventually become quite mainstream). So too, but on the other side of the political fence, many Austrian economists - while broadly sympathetic to much of what Robbins had to say - were critical of specific aspects of his approach. Finally, if one is using the term "mainstream" in any meaningful way regarding economics during the first half of the twentieth century, then one would certainly need to count Marshallians as part of the mainstream, and yet Marshallians generally did not accept Robbins's arguments against interpersonal utility comparisons. In light of all this it is probably best to think of the "economics profession" as those economists generally endorsing some version of marginalist/neoclassical economics, but remember that even here there were critics of Robbins's position (particularly with respect to interpersonal utility comparisons). 
accepting the no-longer-scientifically-acceptable hedonistic characterization of the individual economic agent. This has been called the "empiricist motive" for the "escape from psychology" (Giocoli, 2003, p. 43) - and in a sense that is exactly what it was - but one needs to be careful about both the terms "empiricist" and "psychology." The scientific credibility problem centered around psychological hedonism - that was the brand of "psychology" that the profession needed to escape from because hedonistic psychology was based on the subjective mental-statebased feelings of individual agents and thus was not "empirical" in the way that "empirical" had come to be used by philosophers and scientists by the 1930 s. Finding a way to characterize marginalism that was more epistemically acceptable - thus rejecting psychological hedonism - was thus the core of the scientific credibility problem.

But the scientific credibility problem was not the only problem marginalism faced in the 1930s. If it were, then some version of behaviorism would have been the easy solution (again recall that was Paul Samuelson's goal in 1938). There were many other issues and constraints, but the one that seems most relevant to Robbins's Essay was the need to retain the notion that economic action was about choice (constrained, but still voluntary, choice). For Robbins the lesson of Robinson Crusoe is that the economic aspect of human behavior economizing - is necessarily choosing behavior:

$\ldots$ he has to choose. He has to economise. Whether he chooses with deliberation or not, his behaviour has the form of choice. The disposition of his time and his resources has a relationship to his system of wants. It has an economic aspect. (Robbins, 1932, p. 12, emphasis added)

As argued above, the laws of stimulus and response at the center of behaviorism left no room for a scientific theory of voluntary choice. ${ }^{7}$ The relationship between stimulus and response take the form of universal scientific laws; given $\mathrm{x}, \mathrm{y}$ could not have been otherwise. On the other hand, if the behavior is the result of a choice, it could always have been otherwise. Choice is at the heart of what distinguishes market economies from other economic institutions and it is also what distinguishes (rational) purposive human behavior from the (biologically) purposive behavior of other living creatures, and as such, free volitional choice (not conditioned response) was something that most economists found essential to economic science. This is the reason that economics was a

\footnotetext{
7 Of course behaviorism is not alone in this respect. The mechanical forces of late nineteenth century psychophysiology have the same difficulty and do (more recent) positions within the philosophy of mind such as eliminative materialism (see Hands 2007).
} 
moral science for John Stuart Mill, and although the term "moral" was not longer used in the 1930s, the idea of individual choice (thus excluding physical, neurochemical, biological, or behaviorist theories of human behavior) continued to be essential to the science of economizing. In contrast to the scientific credibility problem, this was the choice problem.

While there were clearly other issues facing marginalism during the 1930s - the Great Depression for example - it seems to be quite clear that both the scientific credibility problem and the choice problem were serious issues. If marginalism was to move forward and take its place as the cornerstone of scientific economics it would be necessary to provide an effective response to these two problems: place marginalism on firmer foundations by eliminating its ties to hedonistic psychology and do so without sacrificing the key role of the freely choosing economic agent. Despite the various tensions discussed above, providing what seemed to be an acceptable solution to these two problems is exactly what Robbins did. The Essay excluded both psychological hedonism and behaviorism from economics; excluding hedonism addressed the scientific credibility problem while excluding behaviorism addressed the choice problem. He was not alone of course - the ordinal revolution of Pareto, Slutsky, Hicks $\&$ Allen and others certainly played a role - but the Essay clearly made a fundamental contribution.

Notice that this contribution did not just come about in spite of the tensions discussed in the previous section, but rather because of them. A position with fewer such philosophical tensions - strict behaviorism on one hand, or a return to Mill's methodological position on the other would have run aground on either the scientific credibility problem or the choice problem. Behaviorism would have provided an effective solution to the former, and Mill's methodology to the latter, but Robbins's Essay seemed to offer an effective solution to both. Thus it not only becomes clear why Robbins needed all of the various pieces that he assembled in the Essay, but also why the finished product was so well received.

\section{4. $\underline{\text { Conclusion }}$}

I have argued that there were fundamental tensions in Robbins's Essay and that the tensions are essential rather than accidental. The tension is exactly what allowed Robbins to defend the Essay's three main theses his definition of economics, replacing psychological hedonism with a more acceptable foundation for choice theory, and making the case against interpersonal utility comparisons - but it was also precisely what marginalist economics needed in response to the broader scientific credibility problem and the choice problem of the 1930s. Effective 
solutions to problems often involve trade-offs and substitution at the margin - in methodology as in economic life.

I would like to close this discussion of Robbins's Essay and the problem situation of economics in the 1930s with a few more speculative remarks about how the lesson we garnered from Robbins's work might have something to say about the current situation in economic science. The profession is currently experiencing an explosion of research activity in a number of subfields that did not exist even a decade or so ago behavioral economics, experimental economics, behavioral finance, neuroeconomics, and others - and in many ways the results of these new fields challenge the "solution" in Robbins's Essay. Clearly many of the results of experimental and behavioral economics challenge the standard assumptions of rational choice theory - in particular the assumption of the stable, consistent, and given "ends" (i.e. preferences) - and we seem to again be at a time where the demand for greater consideration of recent developments in psychology is increasing. One approach to trying to understand why these changes are taking place and to understand the possible impact on the profession is to consider the arguments directly on a case by case basis: Is this result valid? Is this experiment wellconstructed? Is it relevant to agents in "the wild"? Is there a way to amend rational choice to integrate this particular anomaly? And so forth. This is of course extremely important; we do need to understand the details of the particular models, experiments, and anomalies that are challenging the rational choice received view. But the above discussion of Robbins suggests other approaches as well. In order to understand Robbins's Essay I tried to demonstrate that it was useful to understand Robbins's particular problem situation - the various goals and constraints he faced - and that in order to understand the impact of the Essay (despite, or because of, various tensions) it was useful to understand the profession's problem situation during the 1930s. So to perhaps for the situation today. Historians and methodologists of economics have certainly started to investigate the former - the problem situations of various key theorists and research groups within these newly developing literatures (Bruni and Sugden 2007, Guala 2004, Lee and Mirowski 2007, Sent 2004 and many others) - but perhaps it is time to consider the problem situation of the profession more generally. What are the contemporary analogues of the scientific credibility problem and the choice problem faced by 1930s marginalism? How did they come about? And how does the research in behavioral, experimental, and neuro- economics provide a solution to the contemporary problem situation? As I said, this is speculative, but it is a way that the above discussion of Robbins's Essay might give us a better understanding of recent developments within the discipline. 


\section{$\underline{\text { References }}$}

Backhouse, Roger and Medema, Steve (2007), "Defining Economics:

Robbins's Essay in Theory and Practice," paper presented at the History of Economics Society Annual Meeting, George Mason University, June 8$11,2007$.

Blaug, Mark (1992), The Methodology of Economics: Or How Economists Explain. $2^{\text {nd }}$ edition, Cambridge: Cambridge University Press.

Bruni, Luigino and Sugden, Robert (2007), "The Road Not Taken: How Psychology was Removed from Economics and How it Might be Brought Back In," The Economic Journal, 117, 146-73.

Caldwell, Bruce J. (1994), Beyond Positivism: Economic Methodology in the Twentieth Century. $2^{\text {nd }}$ edition, London: Routledge.

Friedman, Milton (1953), "The Methodology of Positive Economics," in Essays in Positive Economics, Chicago: University of Chicago Press, 343.

Giocoli, Nicola (2003), Modeling Rational Agents: From Interwar Economics to Early Modern Game Theory. Cheltenham: Edward Elgar.

Guala, Francesco (2005), The Methodology of Experimental Economics. Cambridge: Cambridge University Press.

Hands, D. Wade (2001), Reflection Without Rules: Economic Methodology and Contemporary Science Theory. Cambridge: Cambridge University Press.

Hands, D. Wade (2007), "Economics, Psychology, and the History of Consumer Choice Theory" Available at SSRN:

http://ssrn.com/abstract $=988125$

Hicks, John (1982), "Introductory: LSE and the Robbins Circle," in Money, Interest and Wages: Collected Essays on Economic Theory, Volume III, Cambridge, MA: Harvard University Press, 3-10.

Hicks, John R. and Allen, R. G. D. (1934), "A Reconsideration of the Theory of Value, Parts I and II," Economica, 2, 52-76, 196-219. 
Howson, Susan (2004), "The Origins of Lionel Robbins's Essay on the Nature and Significance of Economic Science," History of Political Economy, 36, 413-443.

Hutchison, Terence (1938), The Significance and Basic Postulates of Economic Theory. London: Macmillan.

Kahneman, Daniel and Krueger, Alan B. (2006), "Developments in the Measurement of Subjective Well-Being," Journal of Economic Perspectives, 20, 3-24.

Lee, Kyu Sang and Mirowski, Philip (2007), "The Energy Behind Vernon Smith's Experimental Economics," Cambridge Journal of Economics [forthcoming].

Little, I. M. D. (1949), "The Foundations of Welfare Economics," Oxford Economic Papers, 1, 227-46.

Mill, John Stuart (1874), "On the Definition of Political Economy; and on the Method of Investigation Proper To It," In Essays on Some Unsettled Questions of Political Economy, 2nd edition, London: Longmans, Green, Reader \& Dyer [Augustus M. Kelley reprint 1968, $1^{\text {st }}$ edition 1844].

O'Brien, D. P. (1990), "Lionel Robbins and the Austrian Connection," in Carl Menger and His Legacy in Economics, B. J. Caldwell (ed.), Durham, NC: Duke University Press [Annual Supplement to Volume 22 of History of Political Economy], 155-84.

Robbins, Lionel (1932), An Essay on the Nature \& Significance of Economic Science. London: Macmillan \& Co.

Robbins, Lionel (1934), "Remarks on the Relationship Between Economics and Psychology," Manchester School of Economic and Social Studies, 5, 89-101.

Robbins, Lionel (1938), "Interpersonal Comparisons of Utility: A Comment," The Economic Journal, 48, 635-41.

Robbins, Lionel (1952), An Essay on the Nature \& Significance of Economic Science. $2^{\text {nd }}$ Edition, London: Macmillan \& Co. [Reprint of $19352^{\text {nd }}$ Edition].

Robbins, Lionel (1953), "Robertson on Utility and Scope," Economica, 20, 99-111. 
Robbins, Lionel (1981), "Economics and Political Economy," American Economic Review, 71, 1-10.

Samuelson, Paul A. (1938), "A Note on the Pure Theory of Consumer's Behaviour," Economica, 5, 61-71.

Sent, Esther-Mirjam (2004), "Behavioral Economics: How Psychology Made Its (Limited) Way Back Into Economics," History of Political Economy, 36, 735-60.

Skinner, B. F. (1974), About Behaviorism. New York: Vintage.

Watson, John (1924), Behaviorism. New York: W. W. Norton.

Walsh, Vivian (1996), Rationality, Allocation, and Reproduction. Oxford: Clarendon Press. 